\title{
Advancement of CMOS Schmitt Trigger Circuits
}

\author{
Wassan M. Kader ${ }^{1}$, Haroon Rashid ${ }^{1}$, Md. Mamun ${ }^{1} \&$ Mohammad Arif Sobhan Bhuiyan ${ }^{1}$ \\ ${ }^{1}$ Department of Electrical, Electronic and Systems Engineering, Universiti Kebangsaan Malaysia, Malaysia \\ Correspondence: Md. Mamun, Department of Electrical, Electronic and Systems Engineering, Universiti \\ Kebangsaan Malaysia, Bangi 43600, Malaysia. Tel: 60-3-8921-6311. E-mail: mdmamun.ukm@gmail.com
}

Received: August 6, 2012 Accepted: November 9, 2012 Online Published: November 21, 2012

doi:10.5539/mas.v6n12p51 URL: http://dx.doi.org/10.5539/mas.v6n12p51

\begin{abstract}
Schmitt triggers are electronic comparators that are widely used to enhance the immunity of circuits to noise and disturbances and are inherent components of various emerging applications. Conventional Schmitt triggers, composed of operational amplifiers, suffer from some inevitable drawbacks which are not prominent in CMOS Schmitt triggers. In this paper, a review on the advancement of Schmitt trigger circuits are illustrated in different literatures is discussed with their merits and demerits.
\end{abstract}

Keywords: CMOS, schmitt trigger, operational amplifier

\section{Introduction}

The regenerative comparator or Schmitt trigger, introduced by Otto Schmitt in the 1930s (Schmitt, 1938), has been commonly used in the field of communication and signal processing techniques for improving on/off control, reducing the noise effects in triggering devices, analogue to digital conversion (Mohd-Yasin, Tan, \& Reaz, 2004; Chavez, 1995) and a number of other emerging applications including frequency doublers, retinal focal-plane sensors, sub-threshold SRAM, image sensors, pulse width modulation circuits, wireless transponders, FPGA based system and sensors etc. (Akter, Reaz, Yasin, \& Choong, 2008; Yuan, 2009; Reaz et al., 2003; Romli, Mamun, Bhuiyan, \& Hussain, 2012; Reaz et al., 2005).

The term trigger is used because of the output, which remains in its state until the input level changes abundantly by triggering a change. This threshold's dual function is called hysteresis and shows that the Schmitt trigger has some memory as well. Actually it is a bistable multivibrator circuit which converts a varying voltage into an unvarying logical voltage signal (zero or one). Numerous design and implementation of Schmitt trigger circuits for different applications and advantages has been proposed in literatures by many researchers (Lotze \& Manoli, 2012; Saini, Veeramachaneni, Kumar, \& Srinivas, 2009; Kulkarni, Kim, \& Roy, 2007; Wu \& Chiang, 2004; Morimura et al., 2004; Kim, Kim, \& Chung, 2007; Dokic, 1984; Dokic \& Bundalo, 1985; Wang, 1991; Kim, Joongsik, \& Kim, 1993; Dokic, 1996; Zhang, Srivastava, \& Ajmera, 2003; Franco, 1988; Dokic, 1984; Azeemuddin \& Sayeh, 2011; Chen \& Ker, 2005; Kuang \& Chuang, 2001; Stayaert \& Sansen, 1986; Singhanat et al., 2011; Ahdal \& Toumazou, 2012). This paper presents a detail review on the merits and demerits of each circuit from its architecture and performance point of view illustrated in literatures for last two decades. The article is organized as follows: in Section 1, basic description, history and applications of Schmitt trigger circuit is dicussed while the principle of operation of traditional Schmitt triggers is illustrated in Section 2, Section 3 discuss about the advancement of Schmitt trigger in perspective of their circuit structures and performances and the summury of the review is stated in Section 4.

\section{Working Principle of a Traditional Schmitt Trigger}

Since its invention, the Schmitt trigger circuit has relied on changing the voltage or current threshold levels by means of positive feedback in the analogue loop. In their textbook, Millman and Halkias (1972) discuss how this is done by means of a resistive voltage divider. Other voltage mode feedback circuits, which are more suitable for VLSI implementation, are discussed by Stayaert and Sansen (1986) and Dokic, Iliskovic, and Bundelo (1988). Schmitt trigger circuits with current feedback are discussed by Filanovsky (1988) and Wang and Guggenbuhl (1988).

Schmitt trigger is one kind of regenerative circuit, mainly worthwhile in digital systems (Marufuzzaman, Reaz, Rahman, \& Ali, 2010; Akter, Reaz, Yasin, \& Choong, 2008). Schmitt Trigger is usually composed of a comparator which has two different levels of threshold voltages. If the input voltage level is high, the output 
voltage of comparator will switch to high (in the case of standard Schmitt trigger) or low (in the case of inverting Schmitt trigger) whereas the output voltage will stay in the same state until the input voltage level turns to the low level of threshold voltage. Here, high voltage level refers to the positive voltage of comparator whereas the low level voltage refers to the negative voltage. Threshold voltage of the circuit is calculated by the given formula (Stayaert \& Sansen, 1986):

$$
\begin{aligned}
& \mathrm{V}_{\text {threshold }}=\left(+\mathrm{V}_{\text {supply }}\right) \times\left(\frac{\mathrm{R}_{I}}{R_{F B}+R_{I}}\right) \\
& \mathrm{V}_{\text {threshold }}=\left(-\mathrm{V}_{\text {supply }}\right) \times\left(\frac{\mathrm{R}_{I}}{R_{F B}+R_{I}}\right)
\end{aligned}
$$

To operate the Schmitt trigger, a comparator must need to have a positive and a negative power supply. Figure 1 and Figure 2 represents the basic circuit diagrams of a standard and an inverting Schmitt Trigger circuit respectively. Figure 3 provides the behavior of a Schmitt Trigger against an alternating voltage.

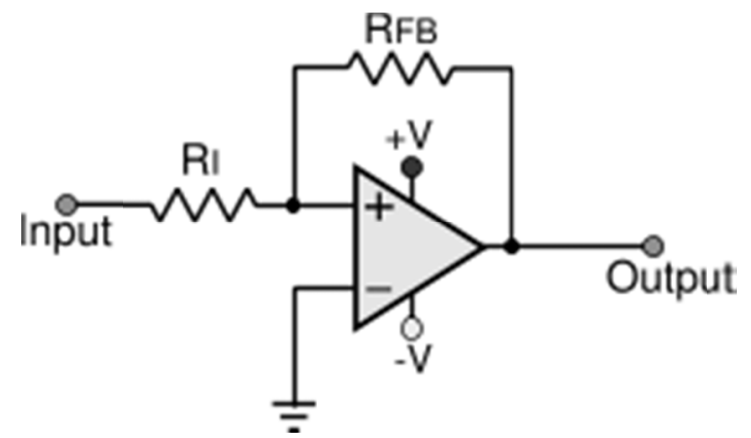

Figure 1. A standard non-inverting schmitt trigger circuit

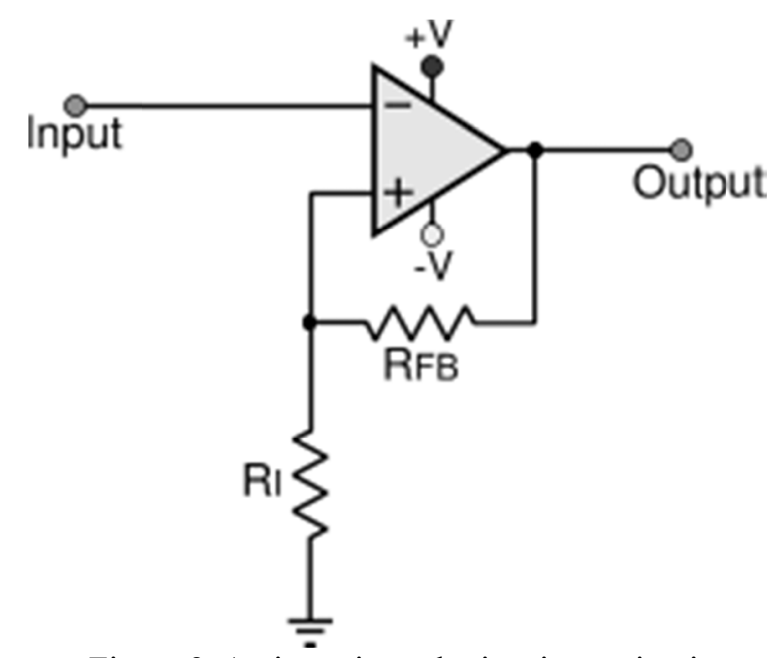

Figure 2. An inverting schmitt trigger circuit 


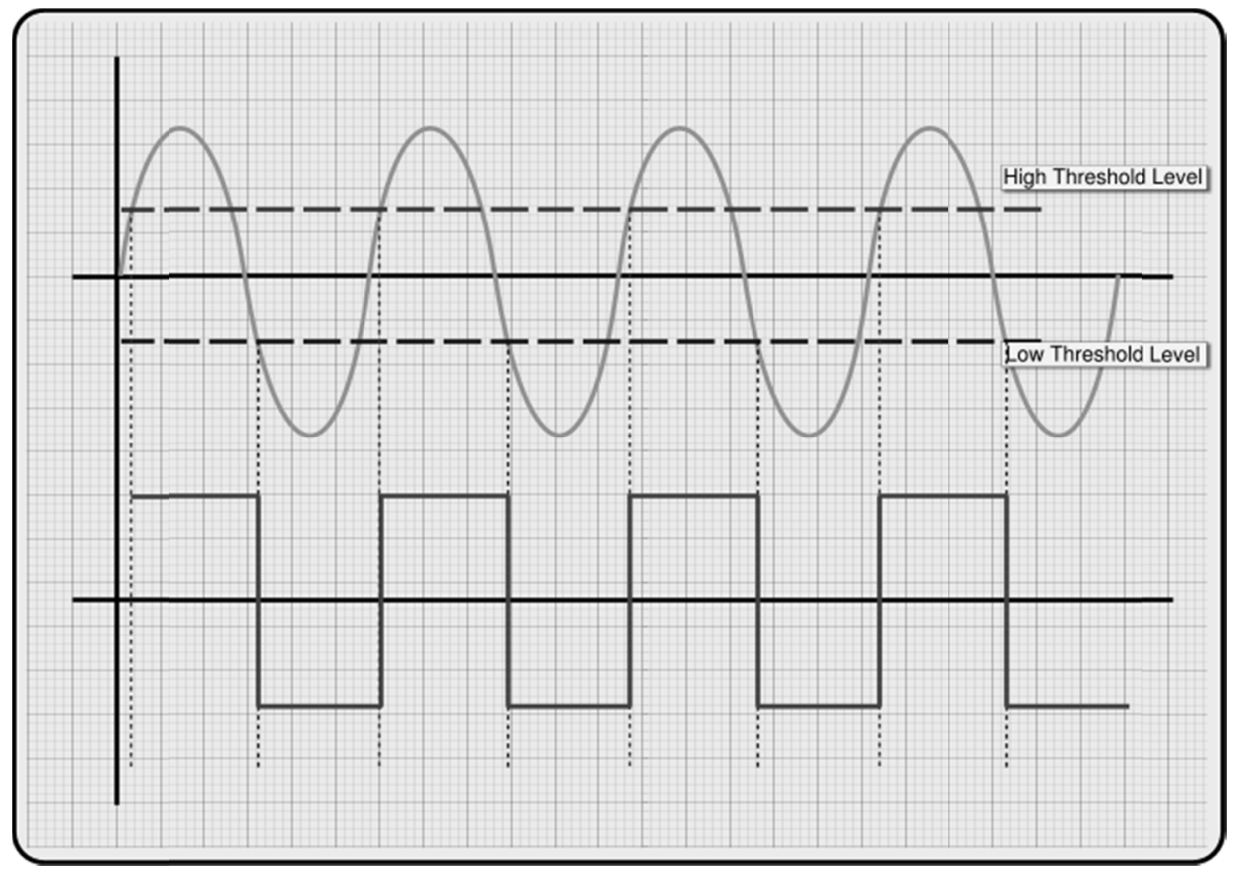

Figure 3. Working principle of schmitt trigger

$\mathrm{AC}$ input is represented here in orange colour. The dotted red and blue colour lines horizontally are indicating high and low threshold level of voltages respectively while the green colour square wave is showing the output by Schmitt Trigger. When the input voltage exceeds the threshold level (high), the output of the Schmitt trigger will rise to high and when input voltage level beats the threshold level (low), the output of Schmitt trigger will be low. In case of inverting Schmitt trigger, everything is same except that the output is inverted i.e. if the input voltage is higher than the threshold level (high), the output will be low and vice versa.

Traditional Schmitt trigger circuits rely on a voltage or current reference switching principle and therefore, have some common disadvantages such as their reference voltages are usually not independent. Secondly, their reference voltages are also a function of the output voltages. Thirdly, the speed of the analogue switch in the feedback loop becomes critical in high-speed applications (Ramirez, 1995). Besides because of the correctness restriction of resistors and op-amp design tasks e.g. Low offset and high DC gain necessities etc. these sorts of Schmitt trigger circuits are not appropriate for CMOS technology. To overcome these problems and improve the functionalities of Schmitt trigger circuits, research is going on all over the world (Branko, 1996).

\section{Advancements of Schmitt Trigger Circuits}

CMOS Schmitt triggers are circuits that convert a varying voltage into a stable logical signal (one or zero). The basic circuit of the Schmitt trigger-inverter with three pairs of CMOS transistors described by Dokic (1984) is shown in Figure 4. By using conventional CMOS technology, it can be implemented and its construction depends on enhancement transistors and the circuit involves one NMOS inverter $\left(\mathrm{T}^{\prime}{ }_{\mathrm{N}}, \mathrm{T}_{\mathrm{N} 0}\right)$, one conventional CMOS inverter $\left(\mathrm{T}_{\mathrm{N}}, \mathrm{T}_{\mathrm{P}}\right)$ and one PMOS inverter $\left(\mathrm{T}_{\mathrm{P}}, \mathrm{T}_{\mathrm{P} 0}\right)$. 

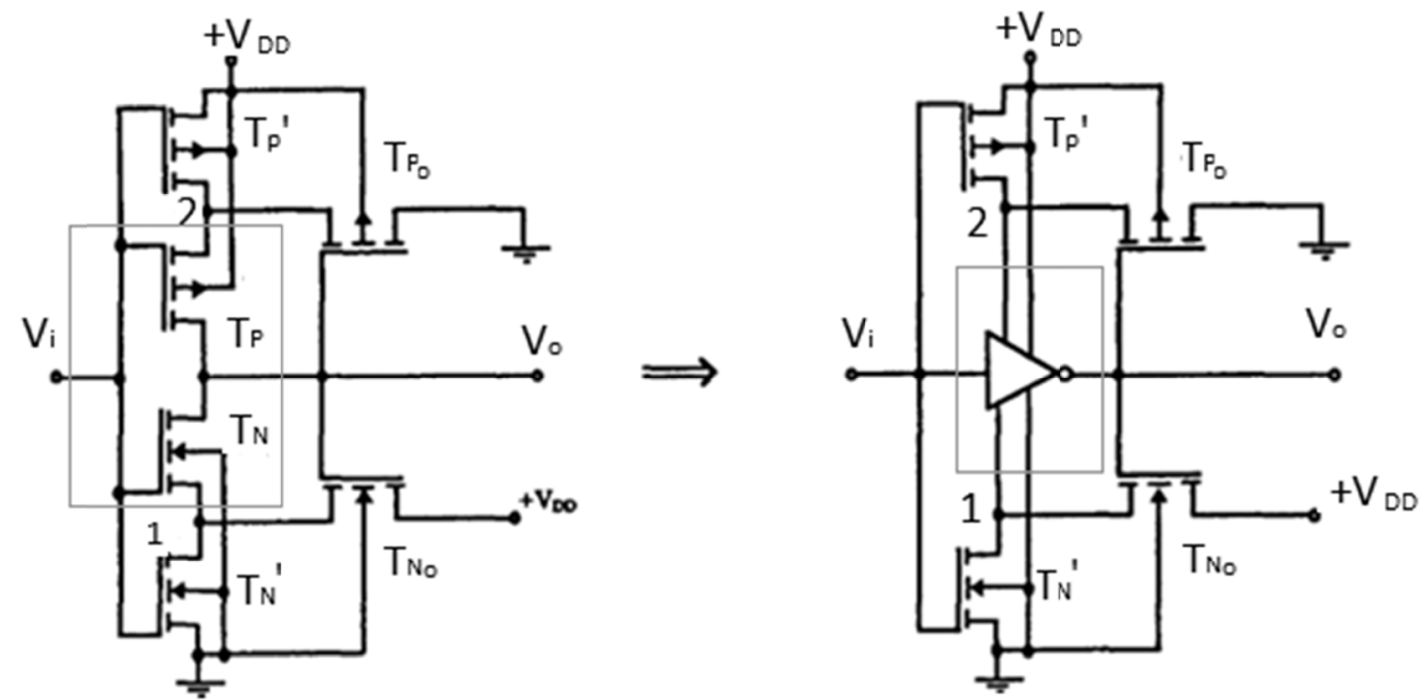

Figure 4. Schmitt trigger-inverter with three pairs of CMOS transistors

The similar rule is proposed to design m-input NOR and NAND Schmitt triggers replacing CMOS inverter by Dokic (1984) (Figure 5 and Figure 6). With the conventional CMOS gates the NAND Schmitt circuit is obtained when pairs of NMOS transistors are in series and PMOSs are parallel and for the NOR Schmitt circuit it is the opposite. The total number of transistors of an m-input circuit is $2(2 \mathrm{~m}+1)$. The output of the NAND circuit is low when all the inputs are high since the NMOS transistors $\mathrm{T}_{\mathrm{nl}}, \ldots, \mathrm{T}_{\mathrm{nm}}$ ' of the conventional CMOS NAND gate are connected in series. On the otherhand, the output of the NOR circuit is high when all the inputs are low since the PMOS transistors $\mathrm{T}_{\mathrm{pl}}, \ldots, \mathrm{T}_{\mathrm{pm}}$ ' of the conventional CMOS NOR gate are connected in series.

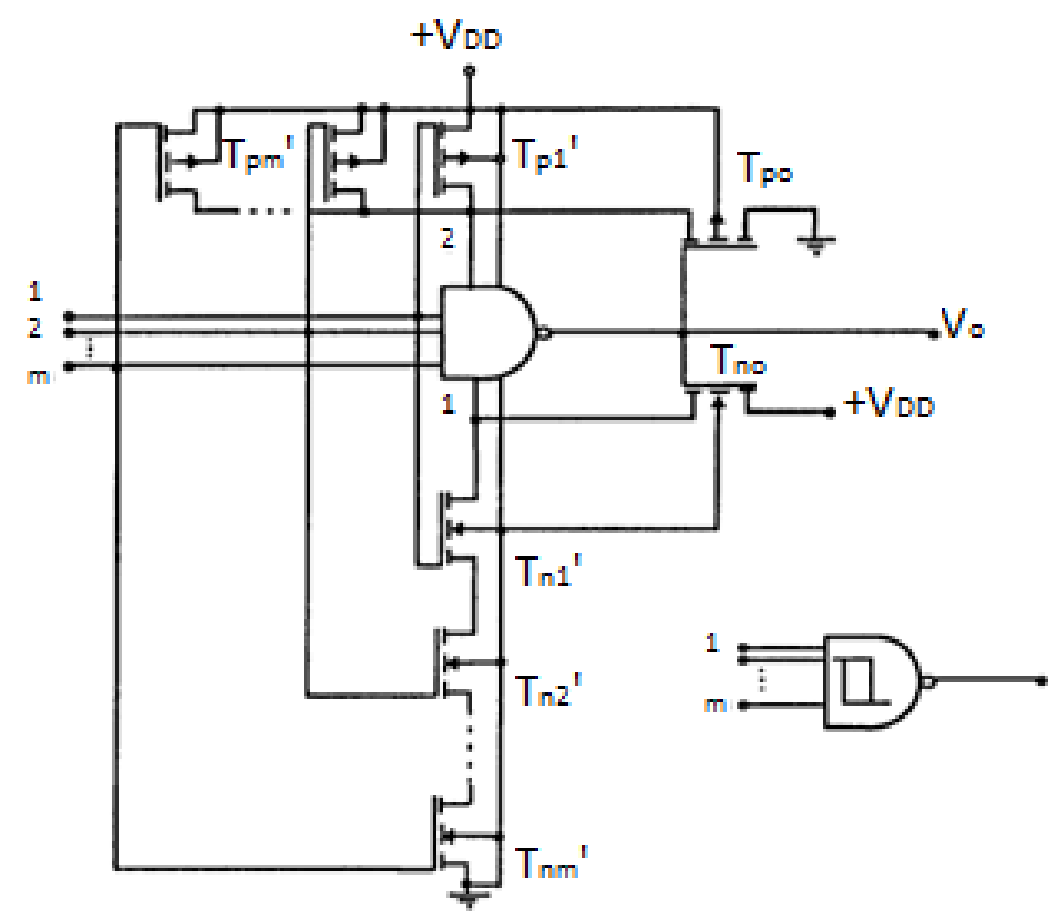

Figure 5. m-Input NAND schmitt circuit 


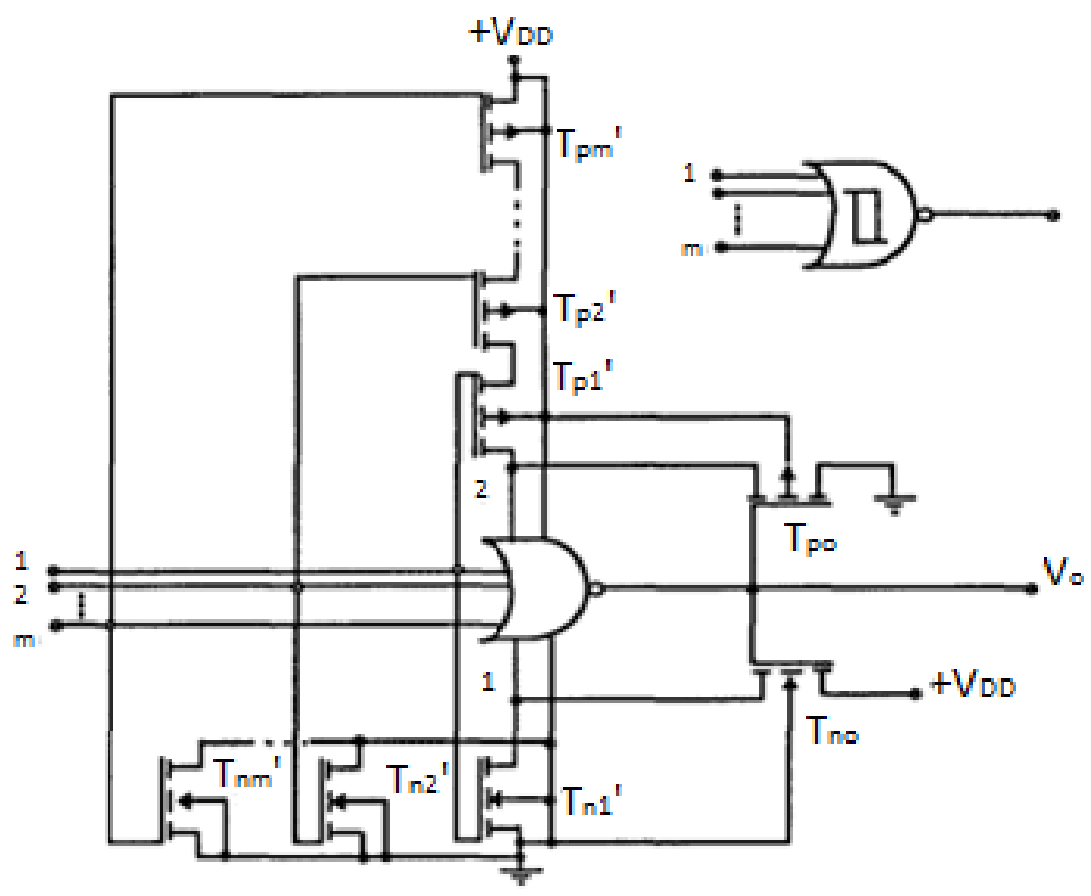

Figure 6. m-Input NOR schmitt circuit

An adjustable low voltage Schmitt trigger circuit for application in CMOS technology was presented by Zhang, Srivastava and Ajmera (2003) (Figure 7(a)). The circuit was technologically advanced based on the Schmitt trigger represented by Singhanath, Kasemsuwan, and Chitsakul (2011) (Figure 7(b)). Dynamic Threshold voltage MOSFET (DTMOS) and body biasing methods are used to permit low voltage operation and regulate the threshold voltage of MOS transistors. Positive feedback is used to advance the on/off output signal and to allow free adjustments of the switching thresholds for positive and negative going input signals.

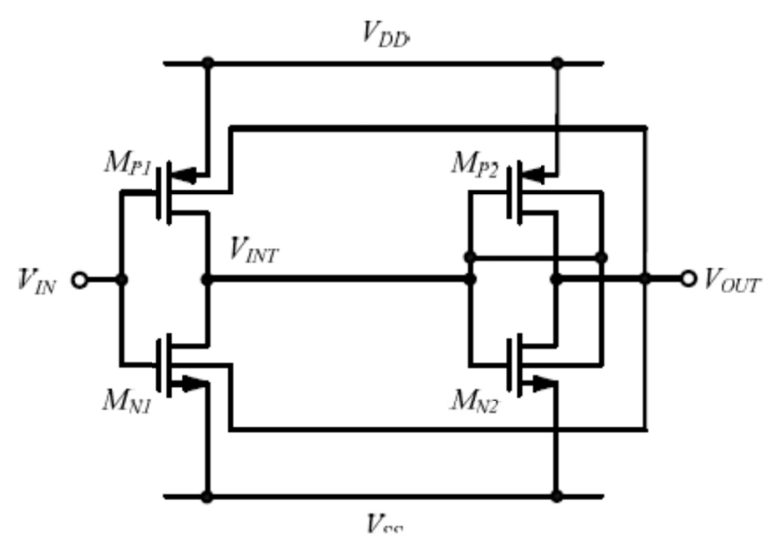

(a)

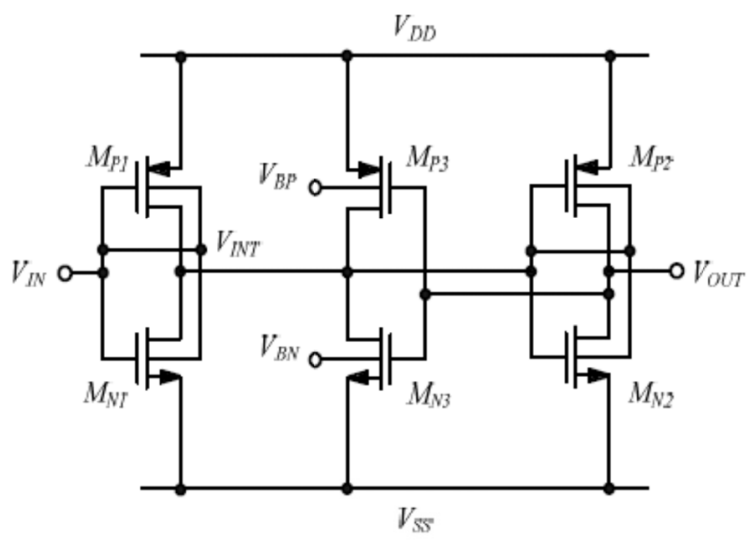

(b)

Figure 7. (a) Low voltage CMOS schmitt trigger, (b) CMOS schmitt trigger

Figure 7(a) shows the construction of Schmitt trigger proposed by Zhang, Srivastava, and Ajmera (2003). The circuit contains two stage CMOS inverters. The first stage works the dynamic-body bias to change the threshold voltage of the transistors $\mathrm{M}_{\mathrm{N} 1}$ and $\mathrm{M}_{\mathrm{P} 1}$, as a result the switching threshold of the inverter. The second stage works DTMOS to make sure that the circuit can operate under low voltage supply. When the input signal $\mathrm{V}_{\text {IN }}$ goes low, the low output signal $\mathrm{V}_{\mathrm{OUT}}$ is fed back to the body of the first inverter and the threshold voltages of $\mathrm{M}_{\mathrm{N} 1}$ and $\mathrm{M}_{\mathrm{P} 1}$ match up to the values at zero substrate bias. It is useful to note that the threshold voltage of $\mathrm{M}_{\mathrm{N} 1}$ is higher and the threshold voltage of $\mathrm{M}_{\mathrm{P} 1}$ is lower than their threshold voltages, compared to the case when the input signal 
$\mathrm{V}_{\mathrm{IN}}$ goes high. End result is, a higher input voltage is required to turn on $\mathrm{M}_{\mathrm{N} 1}$ and turn off $\mathrm{M}_{\mathrm{P} 1}$. On the other side, when the input signal goes high, the high output signal $\mathrm{V}_{\mathrm{OUT}}$ (or $\mathrm{V}_{\mathrm{DD}}$ ) is fed back to the body of $\mathrm{M}_{\mathrm{N} 1}$ and $\mathrm{M}_{\mathrm{P} 1}$. In this scenario, the threshold voltages of $\mathrm{M}_{\mathrm{N} 1}$ and $\mathrm{M}_{\mathrm{P} 1}$ relate to the values at $\mathrm{V}_{\mathrm{DD}}$ substrate bias, creating the threshold voltages of $\mathrm{M}_{\mathrm{N} 1}$ and $\mathrm{M}_{\mathrm{P} 1}$ lower and higher than their threshold voltages, compared to the situation when $\mathrm{V}_{\mathrm{IN}}$ goes low. The end result; a low input voltage is necessary to turn off $\mathrm{M}_{\mathrm{N} 1}$ and turn on $\mathrm{M}_{\mathrm{P} 1}$. These alterations in the changing voltages reason the hysteresis.

Figure 7(b) clarifies the recommended Schmitt trigger circuit of three stage CMOS inverters. DTMOS transistors are employed in the first stage CMOS inverters so that effective transconductance as well as speed of the input stage is increased. The second and third stages are linked as cross-coupled inverters. Transistors $\mathrm{M}_{\mathrm{N} 2}$ and $\mathrm{M}_{\mathrm{P} 2}$ do a similar job as transistors $\mathrm{M}_{\mathrm{N} 2}$ and $\mathrm{M}_{\mathrm{P} 2}$ in Figure 7(a) whereas the third stage inverter $\mathrm{M}_{\mathrm{N} 3}$ and $\mathrm{M}_{\mathrm{P} 3}$ are auxiliary to work for two purposes, they are: firstly, the second and third stage CMOS inverters are coupled in a positive feedback configuration thus speeding up the swapping process and the second one is control voltages of the third stage CMOS inverter control the strength of the feedback signal as a result the switching threshold voltage of the Schmitt trigger.

Schmitt trigger will not react and will be resistant to the unwanted noise if the magnitude of the input signal is less than the switching threshold difference. Numerous methods have been suggested to implement Schmitt trigger. The conventional Schmitt trigger was implemented using operation amplifiers with two resistors connected to its positive feedback configuration (Franco, 1988). This sort of Schmitt trigger is not appropriate in CMOS technology, mainly because of the correctness restriction of resistors and op-amp design tasks e.g. Low offset and high DC gain necessities. Different carrying out of Schmitt triggers can adventure the probable advantages of CMOS technology has been offered (Dokic, 1984). By using only six transistors without latch can be transformed into a Schmitt trigger circuit (Dokic, 1984). The circuit operates with less than 3.3 volts supply without having gate oxide, high voltage overstress. By using a multilayer Schmitt trigger, higher voltage difference between two switching threshold voltages was succeeded as stated by Kuang and Chuang (2001). Unluckily that design needed the stack of four transistors between the power rail and ground rail therefore preventing practice in low voltage applications. Standard CMOS inverter with positive feedback was engaged by Stayaert and Sansen (1986). Only two stacked of transistor used in between ground and power rails. An additional active pull down route was brought in operation for the first inverter while the input was shifting from high to low.

\section{Conclusion}

Schmitt triggers are widely used in different circuits to increase noise immunity by using only single input threshold; the noisy input signal close to the threshold might source the output to switch swiftly back and forth from noise itself. Schmitt trigger's noisy input signal near to threshold can grounds only one switch in output value after which it would have to move away from the other threshold in order to switch another. A common disadvantage of the taking place single ended Schmitt triggers is that; hysteresis is set by process parameters, device dimensions, supply voltage and differs with process situations. Tunable hysteresis is extremely required to overcome this insufficiency. These are analytically needed in applications where disturbances and noise level combined to the triggering signals.

\section{References}

Ahdal, A. A., \& Toumazou, C. (2012). ISFET-based chemical schmitt trigger. Electronics Letters, 48(10), 549-551. http://dx.doi.org/10.1049/el.2011.3781

Akter, M., Reaz, M. B. I., Mohd-Yasin, F., \& Choong, F. (2008). Hardware implementations of an image compressor for mobile communications. Journal of Communications Technology and Electronics, 53(8), 899-910. http://dx.doi.org/10.1134/S106422690808007X

Akter, M., Reaz, M. B. I., Mohd-Yasin, F., \& Choong, F. (2008). A modified-set partitioning in hierarchical trees algorithm for real-time image compression. Journal of Communications Technology and Electronics, 53(6), 642-650. http://dx.doi.org/10.1134/S1064226908060065

Azeemuddin, S., \& Sayeh, M. R. (2011). Effect of various parameters on working of all-optical Schmitt trigger. International Journal for Light and Electron Optics, 122(21), 1935-1938. http://dx.doi.org/10.1016/j.ijleo.2010.12.008

Chavez, S. R. (1995). Mixed-Mode Schmitt Trigger Equivalent Circuit. Electronics Letters, 31(3), 152-154. http://dx.doi.org/10.1049/el:19950107

Chen, S. L., \& Ming-Dou, K. (2005). A new Schmitt trigger circuit in a $0.13-\mu \mathrm{m} 1 / 2.5-\mathrm{V}$ CMOS process to 
receive 3.3- V input signals. IEEE Transactions on Circuits and Systems II: Express Briefs, 52(7), 361-365. http://dx.doi.org/10.1109/ISCAS.2004.1329336

Dokic, B. L. (1984). CMOS Schmitt triggers. IEE Proceedings Electronic Circuits and Systems, 131(5), 197-202.

Dokic, B. L. (1996). CMOS NAND and NOR Schmitt Circuits. Microelectronics Journal, 27(8), 757-765. http://dx.doi.org/10.1016/0026-2692(96)00009-2

Dokic, B. L., Iliskovic, A. J., \& Bundelo, L. V. (1988). CMOS gates with regenerative action at one of inputs. Microelectron. J., 19(3), 17-20. http://dx.doi.org/10.1016/S0026-2692(88)80050-8

Filanovsky, I. M. (1988). A Schmitt trigger with current mirror feedback. Int. J. Electron., 65(4), 837-844. http://dx.doi.org/10.1080/00207218808945284

Franco, S. (1988). Design with Operational Amplifier and Analog Integrated Circuit (3rd edition). New York: McGraw-Hill.

Kim, D., Joongsik, K., \& Kim, W. (1993). A new waveform reshaping circuit: an alternative approach to Schmitt trigger. IEEE J. Solid-State Circuits, 28(2), 162-164. http://dx.doi.org/10.1109/4.192048

Kim, H., Kim, H. J., \& Chung, W. S. (2007). Pulse width Modulation Circuits Using CMOS OTAs. IEEE Transactions on Circuits and Systems I: Regular Papers, 54(9), 1869-1878. http://dx.doi.org/10.1109/TCSI.2007.904677

Kuang, J. B., \& Chuang, C. T. (2001). PD/SOI CMOS Schmitt trigger circuits with controllable hysteresis. IEEE Int. Symp. VLSI Technology and Systems Applications, 283-285. http://dx.doi.org/10.1109/VTSA.2001.934540

Kulkarni, J. P., Kim, K., \& Roy, K. (2007). A $160 \mathrm{mV}$ robust Schmitt trigger based sub-threshold SRAM. IEEE J. Solid-State Circuits, 42(10), 2303-2313. http://dx.doi.org/10.1145/1283780.1283818

Lotze, N., \& Manoli, Y. (2012). A $62 \mathrm{mV} 0.13 \mu \mathrm{m}$ CMOS Standard-Cell-Based Design Technique Using Schmitt-Trigger Logic. IEEE Journal of Solid-State Circuits, 47(1), 47-60. http://dx.doi.org/10.1109/JSSC.2011.2167777

Marufuzzaman, M., Reaz, M. B. I., Rahman, M. S., \& Ali, M. A. M. (2010). Hardware prototyping of an intelligent current dq PI controller for FOC PMSM drive. Proceedings of the 6th International Conference on Electrical and Computer Engineering (ICECE 2010), pp. 86-88. http://dx.doi.org/10.1109/ICELCE.2010.5700559

Millman, J., \& Halkias, C. (1972). Integrated electronics (3rd ed.). New York: McCraw- Hill.

Mohd-Yasin, F., Tan, A. L., \& Reaz, M. I. (2004). The FPGA prototyping of Iris recognition for biometric identification employing neural network. Proceedings of the International Conference on Microelectronics, ICM, pp. 458-461. http://dx.doi.org/10.1109/ICM.2004.1434697

Morimura, H., Shimannura, T., Fujii, K., Shigematsu, S., Okazaki, Y., \& Katsuyuki, M., (2004). A zero-sink-current Schmitt trigger and window-flexible counting circuit for fingerprint sensor/identifier. Proceedings of the IEEE International Solid-State Circuits Conference (ISSCC), pp. 122-517. http://dx.doi.org/10.1109/ISSCC.2004.1332624

Reaz, M. B. I., Islam, M. T., Sulaiman, M. S., Ali, M. A. M., Sarwar, H., \& Rafique, S. (2003). FPGA realization of multipurpose FIR filter. Proceedings of Parallel and Distributed Computing, Applications and Technologies, PDCAT, Aug. 27-29, pp. 912-915. http://dx.doi.org/10.1109/PDCAT.2003.1236448

Reaz, M. B. I., Mohd-Yasin, F., Tan, S. L., Tan, H. Y., \& Ibrahimy, M. I. (2005). Partial encryption of compressed images employing FPGA. Proceedings of the IEEE International Symposium on Circuits and Systems, art. no. 1465105, pp. 2385-2388. http://dx.doi.org/ 10.1109/ISCAS.2005.1465105

Romli, N. B., Mamun, M., Bhuiyan, M. A. S., \& Hussain, H. (2012). Design of a Low Power Dissipation and Low Input Voltage Range Level Shifter in Cedec 0.18- $\mu \mathrm{m}$ Cmos Process. World Applied Sciences Journal, 19(8), pp. 1140-1148.

Saini, S., Veeramachaneni, S., Kumar, A. M., \& Srinivas, M. B. (2009). Schmitt trigger as an alternative to bufferinsertion for delay and power reduction in VLSI interconnects. Proceedings of the IEEE Region 10 Conference (TENCON- 2009), pp. 1-5. http://dx.doi.org/10.1109/TENCON.2009.5396104

Schmitt, O. H. (1938). A thermionic trigger. J. Sci. Insrrum., 15(7), 24-26. 
http://dx.doi.org/10.1088/0950-7671/15/1/305

Singhanath, P., Kasemsuwan, V., \& Chitsakul, K. (2011). DTMOS Schmitt Trigger with Fully Adjustable Hysteresis. Proceedings of the International Conference on Circuits, System and Simulation IPCSIT- 2011, pp. 165-170. http://www.etlibrary.org/?m=fbook\&a=details\&aid=3047

Singhanath, P., Suadet, A., Kanjanop, A., Thongleam, T., Kuankid, S., \& Kasemsuwan, V. (2011). Low Voltage Adjustable CMOS Schmitt Trigger. Proceedings of the 4th International Conference on Modelling, Simulation and Applied Optimization (ICMSAO- 2011), pp. 19-21, pp. 1-4. http://dx.doi.org/10.1109/ICMSAO.2011.5775531

Stayaert, M., \& Sansen, W. (1986). Novel CMOS Schmitt trigger. Electronic Letters, 22(4), 203-204. http://dx.doi.org/10.1049/el:19860142

Wang, Z., \& Guggenbuhl, W. (1988). Novel CMOS current Schmitt trigger, Electron. Lett., 24(24), 1514-1516. http://ieeexplore.ieee.org/xpls/abs_all.jsp?arnumber $=27938$

Wang, Z. H. (1991). CMOS adjustable Schmitt triggers. IEEE Trans. Instrum., 40(3), 601-605. http://dx.doi.org/10.1109/19.87026

Wu, C., \& Chiang, C., (2004). A low-photo current CMOS retinal focal-plane sensor with a pseudo-BJT smoothing network and an adaptive current Schmitt trigger for scanner applications. IEEE Sensors J., 4(4), 510-518. http://dx.doi.org/10.1109/JSEN.2004.828856

Yuan, F. (2009) Current Regenerative Schmitt Triggers With Tunable Hysteresis. Proceedings of the 52nd IEEE International Midwest Symposium on Circuits and Systems (MWSCAS '09), pp. 110-113. http://dx.doi.org/10.1109/MWSCAS.2009.5236141

Zhang, C., Srivastava, A., \& Ajmera, P. (2003). Low voltage CMOS schmitt trigger circuits. IEE Electronics Letters, 39(24), 1696-1698. http://dx.doi.org/10.1049/el:20031131 